\title{
The approach to diagnosis and treatment of chronic constipation: Suggestions for a general practitioner
}

\author{
Pierre Paré MD FRCPC FACG
}

P Paré. The approach to diagnosis and treatment of chronic constipation: Suggestions for a general practitioner. Can J Gastroenterol 2011;(Suppl B):36B-40B.

Chronic constipation is a frequent complaint. Symptoms of obstructive defecation (straining, hard and lumpy stools, or incomplete evacuation) are more frequent and bothersome than the frequency of bowel movements. Patient assessment is clinically based on the presence or absence of red flags. Commonly used therapies (eg, bulk-forming agents, stool softeners and stimulant laxatives) have only been evaluated in small studies of short duration. Polyethylene glycol was shown to be effective and safe in several rigorous trials with durations of more than one year. New drugs (prucalopride, lubiprostone and linaclotide) were shown to be effective and safe in well-designed and rigorous studies. Trials conducted in primary care patients are lacking for all therapies. Biofeedback and behavioural therapies are effective, but should be reserved for selected patients after proper diagnostic evaluation. A practical management algorithm is proposed using a multistep approach favouring early introduction of combined therapies and long-term step-down strategy to the lowest satisfactory regimen.

Key Words: Assessment; Chronic constipation; Obstructive defecation; Therapies

Chro hronic constipation (CC) is a frequent complaint. The estimated Canadian prevalence rate of $\mathrm{CC}$ varies according to the definition used. A population-based study involving 1149 subjects (1) reported rates of $27 \%$ when CC was self-reported and $15 \%$ when based on criteria. The prevalence rates for women are almost double those for men, and are approximately similar for all ages. Based on generic instruments, subjects with CC have a significantly decreased quality of life compared with the normal Canadian population or with subjects with no functional constipation (2). This impairment of quality of life is similar or more severe than that experienced in several other chronic diseases (eg, arthritis, asthma or coronary artery disease). Predictors of poor health-related quality of life are health care seeking, older age and being disabled (2).

Not all individuals who report constipation consult a physician, although women seek health care more often than men. The use of medication to treat constipation in the previous year, self-directed or physician-prescribed, also predicts health care seeking (1). This suggests a lack of satisfaction with their treatment for constipation. In a Canadian primary care study (3), 50\% of the patients with functional constipation rated their treatment as unsatisfactory - the most often used treatments were bulk-forming agents, stimulant laxatives, stool softeners and fruit derivatives. In a survey conducted in the United States (US) (4), again, only $50 \%$ of individuals with CC reported that they were satisfied with their current therapies, which included fibre, and over-the-counter (OTC) and prescription laxatives. Even more patients were unsatisfied with the level of relief of the multiple symptoms of constipation and were dissatisfied with the lack

\author{
La démarche diagnostique et thérapeutique de la \\ constipation chronique : des suggestions au \\ praticien généraliste
}

La constipation chronique est un problème fréquent. Les symptômes de défécation obstructive (efforts, selles dures et grumeleusesou évacuation incomplète) sont plus fréquents et dérangeants que la fréquence des mouvements intestinaux. Sur le plan clinique, l'évaluation des patients se fonde sur la présence ou l'absence de signes avertisseurs. Les principales thérapies (p. ex., agents mucilagineux, agents émollients et laxatifs stimulants) ont été évaluées seulement dans de petites études de courte durée. Plusieurs études rigoureuses de plus d'un an ont démontré que le polyéthylène glycol était efficace et sécuritaire. Des études bien conçues et rigoureuses ont révélé que de nouveaux médicaments (le prucalopride, la lubiprostone et le linaclotide) sont efficaces et sécuritaires. Il n'existe pas d'essais menés auprès de patients en soins primaires à l'égard de toutes ces thérapies. La rétroaction biologique (biofeedback) et les thérapies comportementales sont efficaces, mais il faut les réserver à des patients sélectionnés après une évaluation diagnostique convenable. Un algorithme de prise en charge pratique est proposé, faisant appel à une démarche multiple favorisant l'introduction précoce d'une association thérapeutique et d'une stratégie de sevrage à long terme jusqu'à l'atteinte de la posologie satisfaisante la plus basse.

of predictability of their treatment. During the period from 1993 to 2004, ambulatory visits for constipation in the US increased in all age groups, was greatest for children younger than 14 years of age, concomitantly with a significant increase in the use of polyethylene glycol (PEG) and a decrease in the use of bulking agents (5).

For the practitioner, these factors generate an increasing demand in terms of the quantity and quality of health care services provided to their patients with CC. The present review offers suggestions to improve the management of ambulatory patients with CC. Although similar strategies may also serve the needs of disabled patients, the paucity of research involving this particular group necessitates expert opinion and will not be discussed in the present article.

PATIENT ASSESSMENT
Constipation - a symptom complex
Constipation is a symptom complex that can be clinically grouped into
infrequent bowel movements and difficult defecation (Figure 1).
Arbitrarily, and for research purposes, two or more symptoms are
required to define constipation. The symptoms related to difficult
defecation are the most frequent patient complaints and the most
troublesome $(1,3)$ (Table 1). Infrequent bowel movements (BMs) -
commonly used by physicians to define constipation - were reported
by a significantly smaller proportion of patients. Therefore, based on
these observations, focusing primarily on the frequency of BMs and
not recognizing the dominant symptoms of difficult defecation will not
meet the treatment requirements/expectations of many patients.

Laval University, CHAUQ, Hôpital du St-Sacrement, Quebec City, Quebec

Correspondence and reprints: Dr Pierre Paré, Laval University, CHAUQ, Hôpital du St-Sacrement, 1050 Chemin Ste-Foy, Quebec City, Quebec G1S 4 L8.

Telephone 418-682-7646, fax 418-682-7855, e-mail pierre.pare.cha@ssss.gouv.qc.ca

Received for publication April 12, 2011. Accepted June 10, 2011 


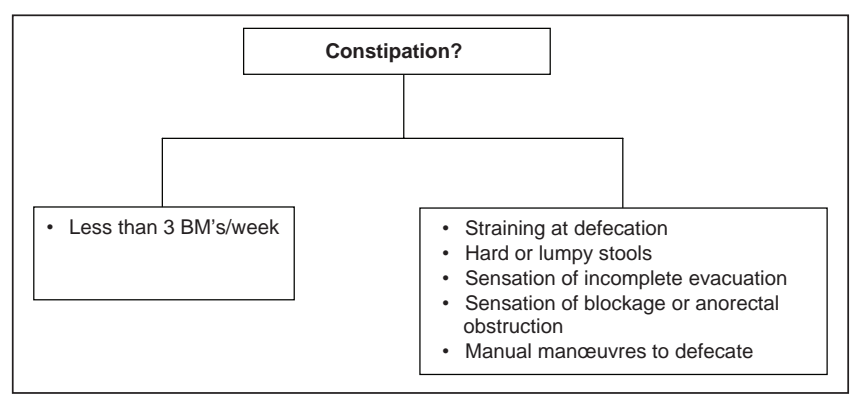

Figure 1) Grouping of constipation symptoms. BMs Bowel movements

\section{Alert to 'red flags'}

Evidence to support the use of blood tests, radiography or endoscopy in the routine workup of patients with constipation without alarm features is lacking (6). CC is defined as functional based on symptoms of at least six months duration and without alarm features (7). Most patients with CC have either functional constipation or constipation-predominant irritable bowel syndrome (IBS-C) in which abdominal pain or discomfort dominates and, therefore, have a macroscopically normal bowel. A suggested approach to assessing patients with CC is shown in Figure 2. No studies have assessed routine blood tests or radiology in patients with $\mathrm{CC}$ (6). Consequently, it has been suggested that the treating physician should judge the need for investigation based on symptom severity, impact on quality of life and the presence of alarm features (7). The red flags listed in Figure 2 are not specific to patients with constipation. Although they may predict a higher OR of finding an organic disease (8), alarm symptoms alone are insufficient to identify patients requiring investigation to rule out organic disease. In the absence of alarm features, health biochemical panel (including complete cell blood count, serum calcium and thyroid- stimulating hormone levels) appears to be appropriate, particularly before referral to a specialist. Furthermore, physicians should follow Canadian guidelines for colorectal cancer based on age and family history. In the presence of red flags, appropriate investigation and/or early referral to a specialist are required.

\section{ASSESSMENT OF CURRENT THERAPIES FOR CC}

In 2007, a group of 10 Canadian gastroenterologists and one family physician published a systematic review of this topic and developed recommendations for treating $\mathrm{CC}$ (7). Although the initiative was not under the auspices of the Canadian Association of Gastroenterology, the group followed a consensus process similar to that outlined by the organization. After elaborating and defining statements with levels of evidence and quality of recommendation, a treatment algorithm was created. Table 2 reports the conclusions derived from the statements made in that review with comments related to new information published since, along with personal opinions from the current author. For most traditional and/or OTC therapies for CC, there is a paucity of high-quality trials (ie, very few randomized, placebo-controlled trials, short study durations, lack of trials conducted in primary care, and very few studies in the elderly and pediatric age groups). For example, in a recent systematic review and meta-analysis of the effect of laxatives and pharmacological therapies in CC using stringent eligibility criteria from 11,077 studies identified in a literature search (9), 49 articles were retrieved for evaluation, with only 20 studies found to be eligible (eight involving laxatives and 12 involving recently developed drugs). However, a management strategy benefits from broader views than one offered by a meta-analysis.

There is insufficient evidence to recommend lifestyle changes such as increased fluid intake or exercise. Physiologically, the volume of water in the daily stools of normal individuals is only approximately $100 \mathrm{~mL}$. Overall, $10 \mathrm{~L}$ to $15 \mathrm{~L}$ of fluid reach the small bowel per day, and $1.5 \mathrm{~L}$ to $2 \mathrm{~L}$ of intestinal fluid enter the colon every day. The small bowel and proximal colon can markedly increase reabsorption of intestinal fluid (10). In a situation in which a patient may be dehydrated or
TABLE 1

Distribution of symptoms in patients with chronic constipation

\begin{tabular}{lcc}
\hline Symptom & $\begin{array}{c}\text { Frequency, \% } \\
\text { (Rome II } \\
\text { defined) }\end{array}$ & $\begin{array}{c}\text { Most } \\
\text { bothersome, \% } \\
\text { (self-reported) }\end{array}$ \\
\hline Straining & 81 & 32 \\
Hard or lumpy stools & 72 & 20 \\
Feeling of incomplete evacuation & 54 & 12 \\
Sensation that stool cannot be passed & 39 & 13 \\
Abdominal fullness or bloating & 37 & 0.4 \\
Fewer than 3 bowel movements/week & 36 & 13 \\
Need to press around the anus & 29 & 6 \\
\hline
\end{tabular}

From reference 1

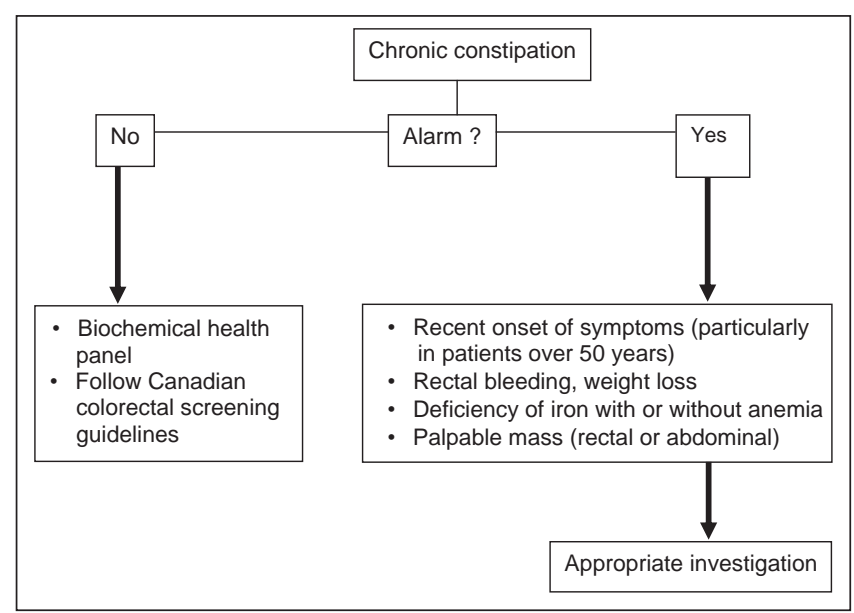

Figure 2) Suggested approach to assessing patients for chronic constipation

drinking very little fluid, increased fluid intake may be important, but likely not in normally hydrated individuals. Exercise only offers symptomatic improvements in CC for elderly patients, particularly those with poor mobility. However, because it improves quality of life and provides other health benefits, exercise can be recommended as part of a general patient-centred health strategy, but not specifically for relieving CC.

Psyllium powder, the most commonly used bulk-forming agent in Canada, has been shown to be more effective than placebo or docusate in patients with CC. Although all previous studies were of short duration (eight weeks or less), clinical experience suggests that the therapeutic benefits of psyllium can be maintained over the long-term. Studies evaluating the efficacy of increased dietary fibre (eg, bran) suggest benefits; however, again, there is a lack of well-designed trials. A very recent analysis (11) reported that there is more supportive evidence for soluble fibre (psyllium) than for insoluble fibre (wheat bran) to be effective in CC. Physicians and patients suggest that intolerance to fibre is common; this belief, however, is not supported by the data. In a primary care, randomized, placebo-controlled study in patients with IBS-C (12), adverse events, including flatulence, occurred frequently and similarly in placebo- and in psyllium-treated or bran-treated patients. A randomized trial (13) recently showed that prunes provided in the form of dried plums were more effective than psyllium in patients with mild to moderate constipation. Their effect may be due to their fibre and sorbitol content. Limitations of this study were that inclusion criteria were not as stringent as in drug trials.

Regardless of whether they are self-directed or health professional recommended, docusate salts are probably the most widely used agents. These agents, compared with placebo, showed no benefit in two studies including 69 patients, while in 15 geriatric patients, increased stool 
TABLE 2

Comments and conclusions derived from the recommendations on chronic constipation

\begin{tabular}{|c|c|c|c|}
\hline & \multicolumn{2}{|c|}{ Recommendation* } & \multirow{2}{*}{ Comments } \\
\hline & Quality & Level & \\
\hline \multicolumn{4}{|l|}{ Bulk-forming agents } \\
\hline Dietary & Uncertain & $\mathrm{D}$ & Gradual increase favourable \\
\hline Psyllium & Effective & B & $\begin{array}{l}\text { Better evidence for psyllium } \\
\text { than bran }\end{array}$ \\
\hline \multicolumn{4}{|l|}{ Stool softeners } \\
\hline Docusate & Insufficient & $\mathrm{C}$ & \\
\hline \multicolumn{4}{|l|}{ Osmotic laxatives } \\
\hline Milk of Magnesia & Effective & $\mathrm{C}$ & $\begin{array}{l}\text { Avoid in patients with renal } \\
\text { insufficiency }\end{array}$ \\
\hline Polyethylene glycol & Effective & A & Unpalatable taste \\
\hline Lactulose & Effective & $\mathrm{B}$ & $\begin{array}{l}\text { May cause bloating, flatulence } \\
\text { and cramping }\end{array}$ \\
\hline \multicolumn{4}{|l|}{ Stimulant laxatives } \\
\hline Short term & Effective & C & $\begin{array}{l}\text { May be associated with } \\
\text { abdominal cramping and } \\
\text { unpredictable nonformed } \\
\text { stools }\end{array}$ \\
\hline \multirow[t]{2}{*}{ Long term } & No evidence & - & $\begin{array}{l}\text { May lead to need for increasing } \\
\text { posology }\end{array}$ \\
\hline & & & $\begin{array}{l}\text { Lubiprostone and linaclotide } \\
\text { are new agents to promote } \\
\text { intestinal secretion }\end{array}$ \\
\hline \multicolumn{4}{|l|}{ Prokinetic agents } \\
\hline Domperidone & Insufficient & $\mathrm{D}$ & $\begin{array}{l}\text { Withdrawn from Canadian } \\
\text { market in } 2007\end{array}$ \\
\hline Tegaserod $^{\dagger}$ & Effective & A & $\begin{array}{l}\text { Prucalopride is a new prokinetic } \\
\text { agent }\end{array}$ \\
\hline $\begin{array}{l}\text { Glycerine } \\
\text { suppositories }\end{array}$ & Effective & $\mathrm{C}$ & $\begin{array}{l}\text { Initiates evacuation by } \\
\text { distending the rectum }\end{array}$ \\
\hline Biofeedback & Effective & B & $\begin{array}{l}\text { Useful in patients with pelvic } \\
\text { floor dysfunction }\end{array}$ \\
\hline $\begin{array}{c}\text { Hypnotherapy/cognitive } \\
\text { behavioural therapy }\end{array}$ & Effective & B & $\begin{array}{l}\text { In selected patients after proper } \\
\text { diagnostic investigation }\end{array}$ \\
\hline
\end{tabular}

*Refer to reference 7 for definitions pertaining to the quality of recommendations and levels of evidence; ' Withdrawn from the Canadian market in 2007

output was, at best, only suggested. Compared with psyllium, docusate salts were less effective. As a group, osmotic laxatives were shown to be effective in improving constipation in randomized, placebo-controlled trials (except milk of magnesia). PEG has been properly assessed in several trials and has been shown to be effective, with a low number needed to treat (NNT) of 2 to 4 . The efficacy and safety of PEG were shown in a study of six months duration (one 8 oz serving daily) (14). In an open-label, 12-month study (15), PEG was shown to be safe and effective, with no evidence of tachyphylaxis in adult and elderly patients with CC.

The vast majority of studies assessing lactulose lasted only two to four weeks, and it was tested against PEG. The latter provided better clinical results with regard to efficacy on bowel function and to side effects. Stimulant laxatives containing senna are very popular and are approved for treatment of occasional constipation, yet are often used chronically, with no available data regarding their long-term efficacy and safety. In recent rigorously conducted trials, bisacodyl (a stimulant laxative) was shown to be effective compared with placebo, and safe in two four-week studies $(16,17)$ and as a rescue agent $(18)$ for CC.

Biofeedback is only useful for severe defecatory disorders (eg, pelvic floor dysfunction) and provides long-term benefits. However, all forms of behavioural therapy are reserved for selected patients and

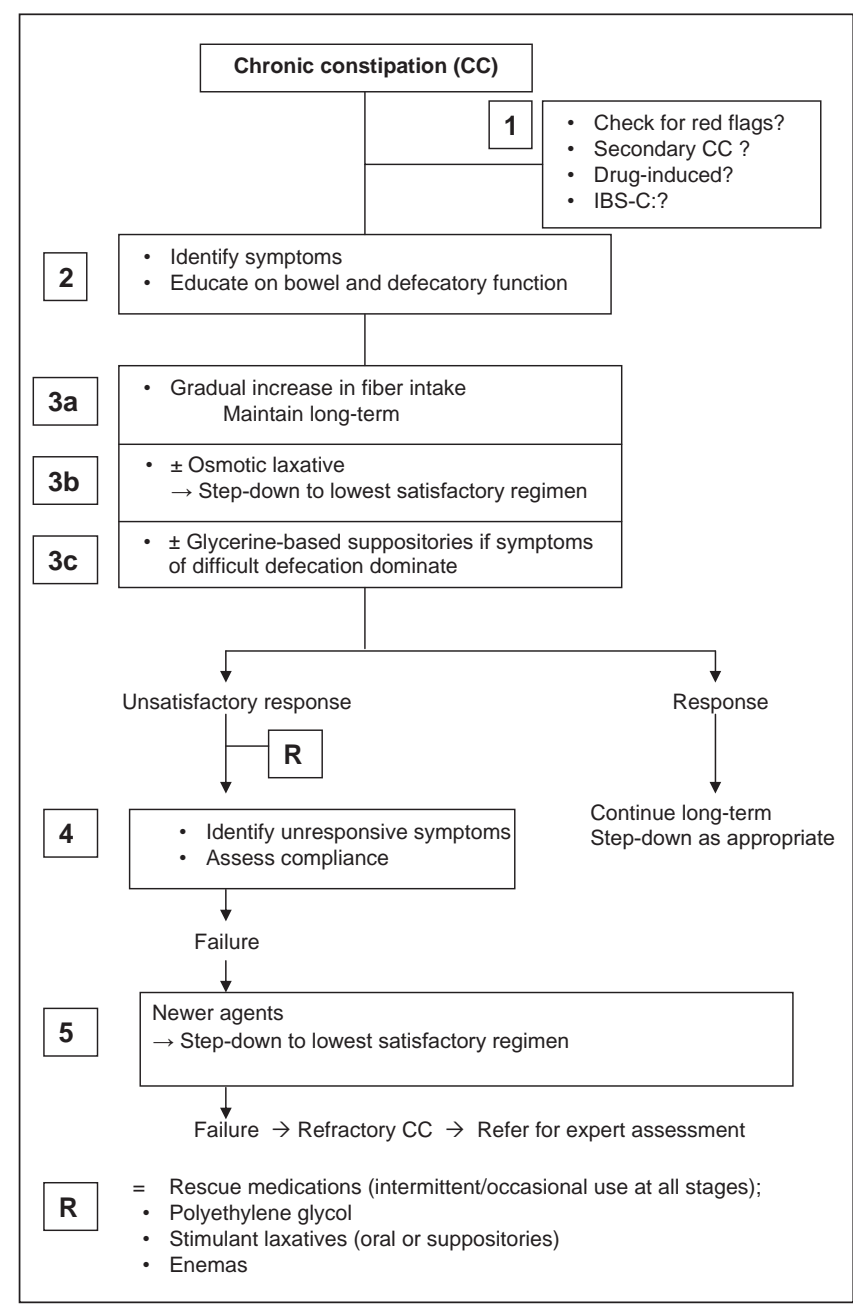

Figure 3) Management algorithm for chronic constipation (CC). IBS-C Constipation-predominant irritable bowel syndrome. Adapted from reference 7

undertaken in specialized centres (19). The value of noninstrumental simple therapies (such as teaching exercises to patients) is unknown.

Newer drugs have recently been evaluated in meta-analyses: prucalopride (studies of four to 12 weeks' duration), lubiprostone (studies of three to four weeks duration) and linaclotide (studies of four to 12 weeks duration). These three drugs were shown to be more effective than placebo, with a low number of total adverse events in rigorous trials. Furthermore, the NNT for all drugs was relatively low (4 to 6) (9).

\section{MANAGEMENT ALGORITHM FOR CC}

The suggested management for CC (Figure 3 ) is a multistep approach including assessment of symptoms, early introduction of combined therapies and long-term step-down strategy to the lowest satisfactory regimen. The algorithm relies on patient- and therapeutically assessed satisfactory results, flexibility guided by the physician and long-term self-management. No clinical trials are available for evaluation of combined therapies because scientific methodology is based on standardized, easily measurable outcomes between two unique interventions.

\section{Step 1}

The diagnosis of functional constipation requires the exclusion of organic diseases and secondary causes of CC. A careful clinical history and physical examination are sufficient to assess for red flags, and to alert for possible secondary and drug-induced causes. Abdominal pain or discomfort is the dominant complaint in patients with IBS-C that overlaps with functional constipation. Dietary fibre and psyllium 
improve constipation and the global symptoms of patients with IBS-C. Antispasmodics also improve global symptoms, with no effect on constipation. Some of the new drugs that may be introduced to the Canadian market (previously discussed) were shown to be more effective than placebo in IBS-C patients.

\section{Step 2}

Step 2 is a crucial part of the assessment. Asking an open-ended question about constipation will generate a positive answer in more than $25 \%$ of individuals, yet no more than approximately one-half of those actually experience at least two symptoms of constipation. A wide variety of common and benign health complaints, such as nausea, dizziness and headache, may be attributable to bowel dysfunction in humans. Even patients meeting Rome II criteria for constipation may not identify themselves as being constipated when it is self-reported (1). Constipation is a symptom complex that must be clinically grouped into difficult defecation and infrequent stools (Figure 1). Obstructive defecation is the most frequent and bothersome symptom reported by patients with CC. In a Canadian primary care study (3), straining and hard or lumpy stools were reported by more than $80 \%$ of patients, while fewer than three BMs per week were reported by only $46 \%$ of the patients. The same proportion of symptoms was observed in IBS-C patients. In a Canadian population-based study (1), straining and hard and lumpy stools were the most bothersome symptoms while fewer than three BMs per week was reported by only $13 \%$ of subjects. Based on these observations, focusing primarily on the frequency of BMs without recognizing the dominant symptoms of obstructive defecation will not be sufficient to meet the needs and expectations of many patients.

Patients must be educated about the variability of bowel function in normal individuals, stool formation from dietary fibre and the mechanism of normal defecation. Attempting to voluntarily control defecation often results in straining. This action should be as simple a manoeuvre as breathing because defecation is a complex phenomenon that starts with the desire initiated by rectal distension, followed by anal relaxation, appropriate descent of the pelvic floor, and expulsatory action by the pelvic and abdominal musculature.

\section{Step 3}

Step 3 is comprised of three components to be proposed early or concomitantly. Fibre works slowly, and early failure may discourage patients to pursue long-term therapy. Subsequently, concomitant use of osmotic laxatives and glycerine suppositories (when defecation is reported to be difficult) will speed the effect of fibre and promote patient satisfaction and compliance with long-term, self-adapted management.

\section{Step 3a}

In a study of more than 1000 patients with severe CC assessed in a tertiary care centre (20), normal-transit constipation through the colon was the most prevalent type ( $58 \%$ of patients), followed by defecatory disorders (25\%), slow-transit constipation $(13 \%)$ and a combination of the two. It can be speculated that the proportion of patients with normal colon transit is much higher in primary care and gastroenterology practices than in specialized centres for CC. Patients with normal colon transit exhibit a good to excellent response to fibre intake (30 g/day for six weeks) (21). Both straining and BM frequency improved. Fibre intake is a determinant of daily stool weight (22). Fibre is an organic polysaccharide that can be insoluble in the diet (eg, wheat and corn bran) or soluble in commercial products (psyllium seed from the plant Plantago ovata). Insoluble fibre acts by encouraging water retention in the stool, while soluble fibre undergoes bacterial fermentation and increases the bacterial mass. Although clinicians commonly report intolerance to fibre, this was not supported in a 12-week, placebo-controlled study using $10 \mathrm{~g} /$ day of psyllium or bran versus placebo (12). Patients with functional constipation or IBS-C have a high load of gastrointestinal symptoms while on placebo. However, due to popular belief, introduction of increasing amounts of fibre is an appropriate strategy. Therapy with fibre should be maintained over the long term, even if the addition of laxatives is needed. Patients often report consuming a high-fibre diet rich in fruits and vegetables; however, no studies examining the treatment of constipation using this strategy are available. Plums and prune juice - well known in the public as natural remedies for constipation - are effective, even more so than psyllium $(6 \mathrm{~g} /$ day, a very small amount for mild to moderate constipation) (13).

There is no evidence that increasing water intake improves the effect of fibre in healthy individuals with CC. However, in elderly or disabled patients, fluid intake may be compromised and, therefore, should be enforced.

\section{Step $3 b$}

Osmotic laxatives are easy to use and the dose can be titrated to a satisfactory response. Milk of Magnesia can be taken irregularly (eg, two to three times per week [ $60 \mathrm{~mL} /$ dose to $90 \mathrm{~mL} /$ dose]) or regularly at a lower dose $(30 \mathrm{~mL} /$ day to $60 \mathrm{~mL} /$ day $)$. Magnesium salts should not be used in patients with renal insufficiency, and used cautiously in elderly patients.

Lactulose use is often limited by its gas-producing effect due to its metabolism by intestinal bacterial flora. No long-term study of Milk of Magnesia or lactulose is available, although these laxatives usually have to be taken on a chronic basis. PEG is an osmotic laxative with the best evidence of efficacy and safety up to one year, taken as one serving per day or as needed. Osmotic laxatives and bisacodyl (a stimulant laxative) accelerate colonic transit $(23,24)$, which may be a class effect.

\section{Step 3c}

Although there is no correlation between disordered defecatory symptoms and physiology (2), symptoms clinically ascribed to difficult defecation are very frequent and do not identify pelvic floor dysfunction per se, paradoxical sphincter contraction (animus) or an organic cause (rectocele, rectal prolapse or rectal hyposensivity). After fibre intake, these symptoms do not improve in the majority of patients, and they may become or remain troublesome in many patients. If symptoms of difficult defecation dominate, glycerin suppositories administered at or before the usual time for the desire to defecate (often after a morning meal) could be used long term as needed with no evidence of dependency.

\section{Step 4}

An unsatisfactory response to therapy should be assessed by reviewing the response of individual symptoms of constipation, the degree of change in quality of life and the adverse effects that could be managed. Patients may have expectations for the relief of symptoms unrelated to constipation or of bowel symptoms, such as bloating and pain, that are not usually responsive to fibre intake and the use of laxatives. A diary recording stool frequency, consistency and ease of defecation could be a useful strategy in understanding patient response to therapy. Education may need to be reinforced to ensure patient compliance with recommended therapies.

\section{Step 5}

Newer drugs will be available in the Canadian market and will probably be approved as a second-line therapy for patients who do not respond to laxatives. Prucalopride is currently under evaluation by Health Canada. Also, patients may have difficulty using osmotic laxatives over the long term and may require other therapies or the use of various drugs in alternating regimens. Aside from the lack of efficacy, fibre and osmotic laxatives can be unpleasant or difficult to take. Prucalopride, provided in tablet form, may offer convenience and, in spite of its probable higher cost compared with current therapies, its NNT of 6 favours its use.

\section{Step R}

Several rescue medications can be used as rapid and short-term strategies to ensure long-term adherence to fibre and osmotic laxatives with or without glycerine suppositories. 


\section{CONCLUSION}

The approaches described focus on first-line agents in the management of CC, owing to their relatively low cost and wide availability. Clinical trials have aimed to assess a single intervention versus a placebo or a control arm; however, in practice, the clinical benefit of the results of these research studies and their applicability should reflect the additive effects of many of these interventions, which would probably surpass the results of individual trials. Often, patients implement one intervention at a time and have experienced a lack of satisfaction. Whether this approach to treating CC yields better results and greater patient satisfaction than the approaches reported in patient

\section{REFERENCES}

1. Pare P, Ferrazzi S, Thompson WG, Irvine EJ, Rance L. An epidemiological survey of constipation in Canada: Definitions, rates, demographics, and predictors of health care seeking. Am J Gastroenterol 2001;96:3130-7.

2. Irvine J, Ferrazzi S, Pare P, Thompson WG, Rance L. Health-related quality of life in functional GI disorders. Focus on constipation and resource utilization. Am J Gastroenterol 2002;97:1986-93.

3. Ferrazzi S. Thompson WG, Irvine EJ, Rance J. Diagnosis of constipation in family practice. Am J Gastroenterol 2002;16:159-64.

4. Johanson JF, Kralstein J. Chronic constipation: A survey of the patient perspective. Aliment Phamacol Ther 2007;25:599-608.

5. Shah ND. Chitkara DK, Locke GR, Meek PD, Talley NJ. Ambulatory care for constipation in the United States, 1993-2004. Am J Gastroenterol 2008;103:1746-53.

6. Rao SSC, Ozturk R, Laine L. Clinical utility of diagnostic tests for constipation in adults: A systematic review. Am J Gastroenterol 2005;100:1605-15.

7. Pare P, Bridges R. Champion MC, et al. Recommendations on chronic constipation (including constipation associated with irritable bowel syndrome) treatment. Can J Gastroenterol 2007;21(Suppl B):3-22

8. Hammer J, Eslick GD, Howell SC, Altiparmark E, Talley NJ. Diagnostic yield of alarm features in irritable bowel syndrome. Gut 2004;53:666-73.

9. Ford AC, Suares NC. Effect of laxatives and pharmacological therapies in chronic idiopathic constipation: Systematic review and meta-analysis. Gut 2011;60:209-18.

10. Schiller LR, Sellin JH. Diarrhea. In: Feldman M, Friedman LS, Brandt LJ, eds. Sleisenger \& Fordtran's Gastrointestinal and Liver Disease. Philadelphia: Saunders, 2010:211-32.

11. Suares NC, Ford AC. Systematic review: The effects of fibre in the management of chronic idiopathic constipation. Aliment Pharmacol Ther 2011;33:895-901.

12. Bijkerk CJ, de Wit NJ, Muris JWM, Whorwell PJ, Knottnerus JA, Hoes AW. Soluble or insoluble fibre in irritable bowel syndrome in primary care? Randomised placebo controlled trial. BMJ 2009;339:b3154-60.

13. Attaluri A, Donahoe R, Valestin J, Brown K, Rao SSC Randomised clinical trial: Dried plums (prunes) vs psyllium for constipation. Aliment Pharmacol Ther 2011;33:822-8. surveys (4) is unknown. Individualizing therapy to allow choices of laxatives and switching between agents during long-term management should be promoted. Targeting therapy to the underlying pathophysiological abnormalities is not a realistic approach in primary care patients in whom no single diagnostic test defines their pathophysiology. In tertiary care-referred patients, testing is probably useful. $(19,25)$.

CONFLICTS OF INTEREST: The author has no financial disclosures or conflicts of interest to declare.

14. DiPalma JA, Cleveland MVB, McGowan J, Herrera JL. A randomized, multicenter, placebo-controlled trial of polyethylene glycol laxative for chronic treatment of chronic constipation. Am J Gastroenterol 2007;102:1436-41.

15. DiPalma JA, Cleveland MV, McGowan J, Herrera JL. An open-label study of chronic polyethylene glycol laxative use in chronic constipation. Aliment Pharmacol Ther 2006;25:703-8.

16. Mueller-Lissner S, Kamm MA, Wald A, et al. Multicenter, 4-week, double-blind, randomized, placebo-controlled trial of sodium picosulfate in patients with chronic constipation. Am J Gastroenterol 2010;105:897-903.

17. Kienzle-Horn S, Vix J-M, Schuijt C, Peil H, Jordan CC, Kamm MA. Comparison of bisacodyl and sodium picosulphate in the treatment of chronic constipation. Curr Med Res Opin 2007;23:691-9.

18. Kienzle-Horn S, Schuijt C, Jordan CC, Kamm MA. Efficacy and safety of bisacodyl in the acute treatment of constipation: A double-blind, randomized, placebo-controlled study. Aliment Pharmacol Ther 2006;23:1479-88.

19. Camilleri M, Bharucha AE. Behavioural and new pharmacological treatments for constipation: Getting the balance right. Gut 2010;59:1288-98

20. Nyam DCNK, Pemberton JH, Ilstrup DM, Rath DM. Long-term results of surgery for chronic constipation. Dis Colon Rectum 1997;40:273-9.

21. Voderholzer WA, Schatke W, Muhldorfer BE, Klauser AG, Birkner B, Muller-Lissner SA. Clinical response to dietary fiber treatment of chronic constipation. Am J Gastroenterol 1997;92:95-8.

22. Davies GJ, Crowder M, Reid B, et al. Bowel function measurements of individuals with different eating patterns. Gut 1986;27:164-9.

23. Manabe N, Cremonini F, Camilleri M, et al. Effects of bisacodyl on ascending colon emptying and overall colonic transit in healthy volunteers. Aliment Pharmacol Ther 2009;30:930-6.

24. Skoog SM, Bharucha AE, Camilleri M, et al. Effects of an osmotically active agent on colonic transit. Neurogastroenterol Motil 2006;18:300-6.

25. Mertz H, Naliboff B, Mayer EA. Symptoms and physiology in severe chronic constipation. Am J Gastroenterol 1999;94:131-8. 


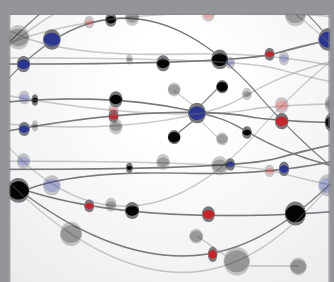

The Scientific World Journal
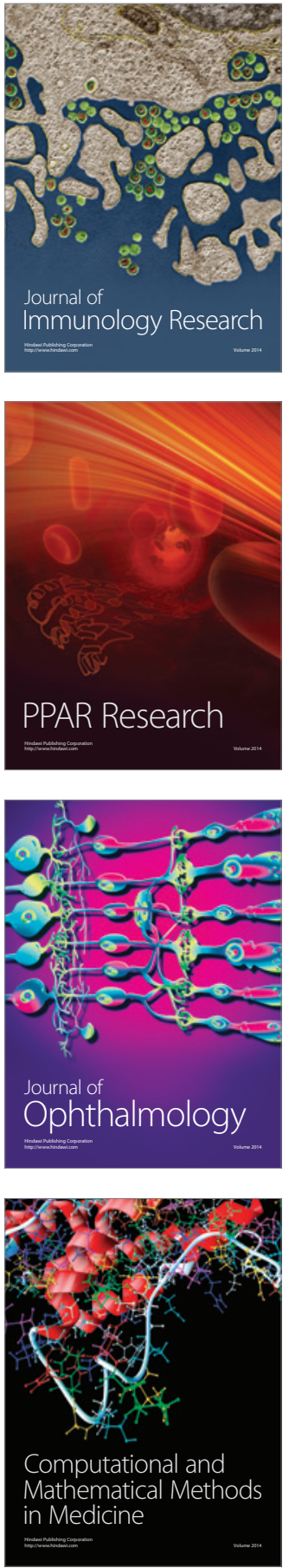

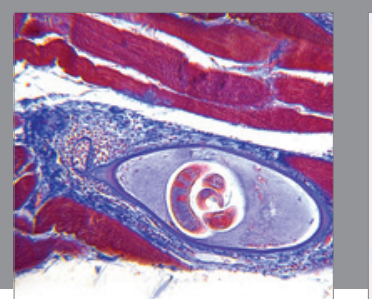

Gastroenterology Research and Practice

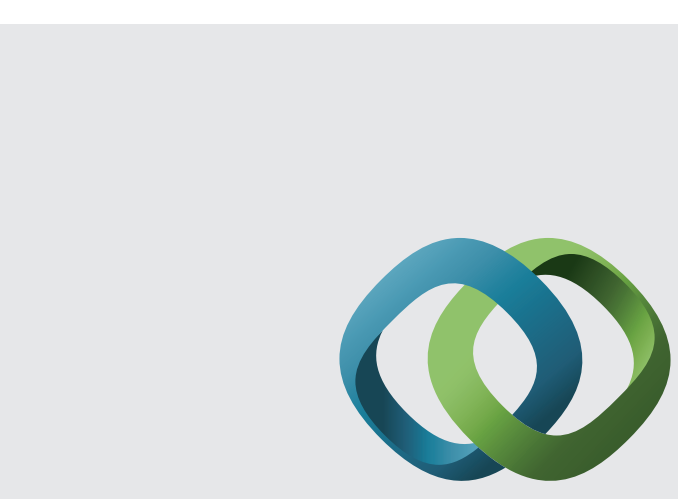

\section{Hindawi}

Submit your manuscripts at

http://www.hindawi.com
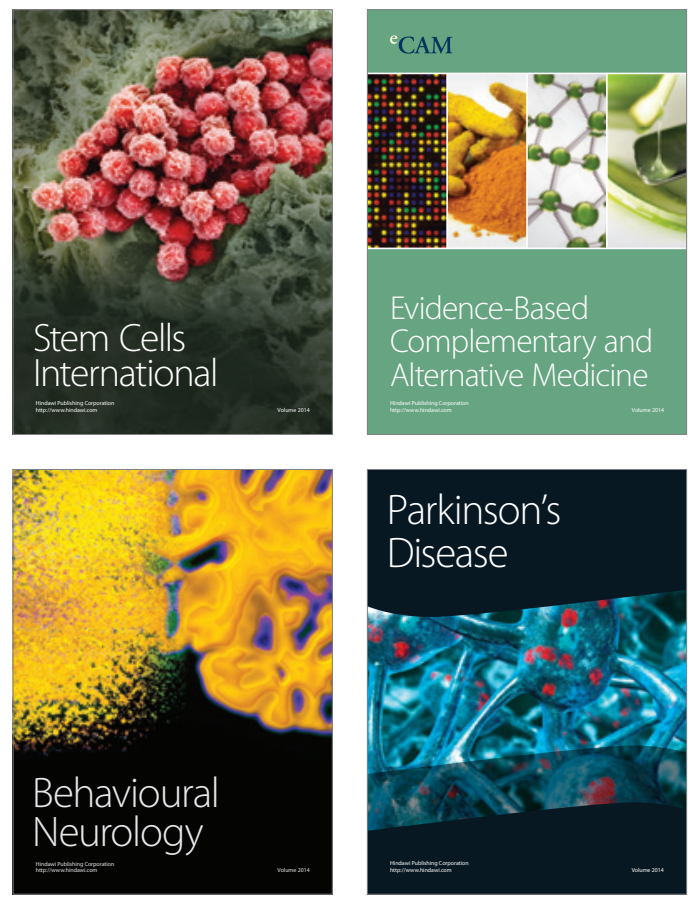
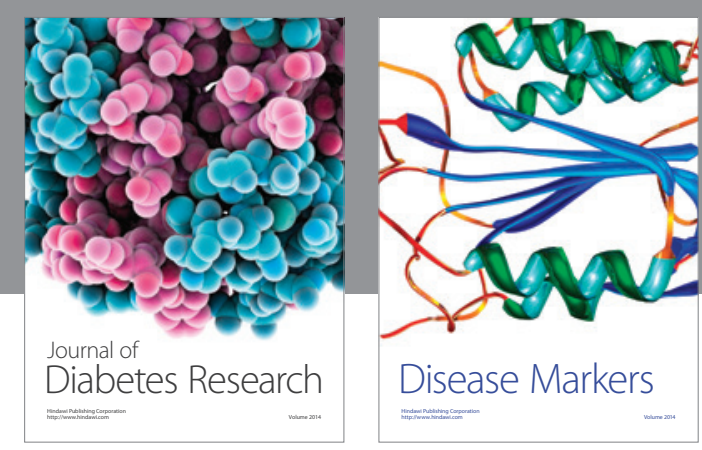

Disease Markers
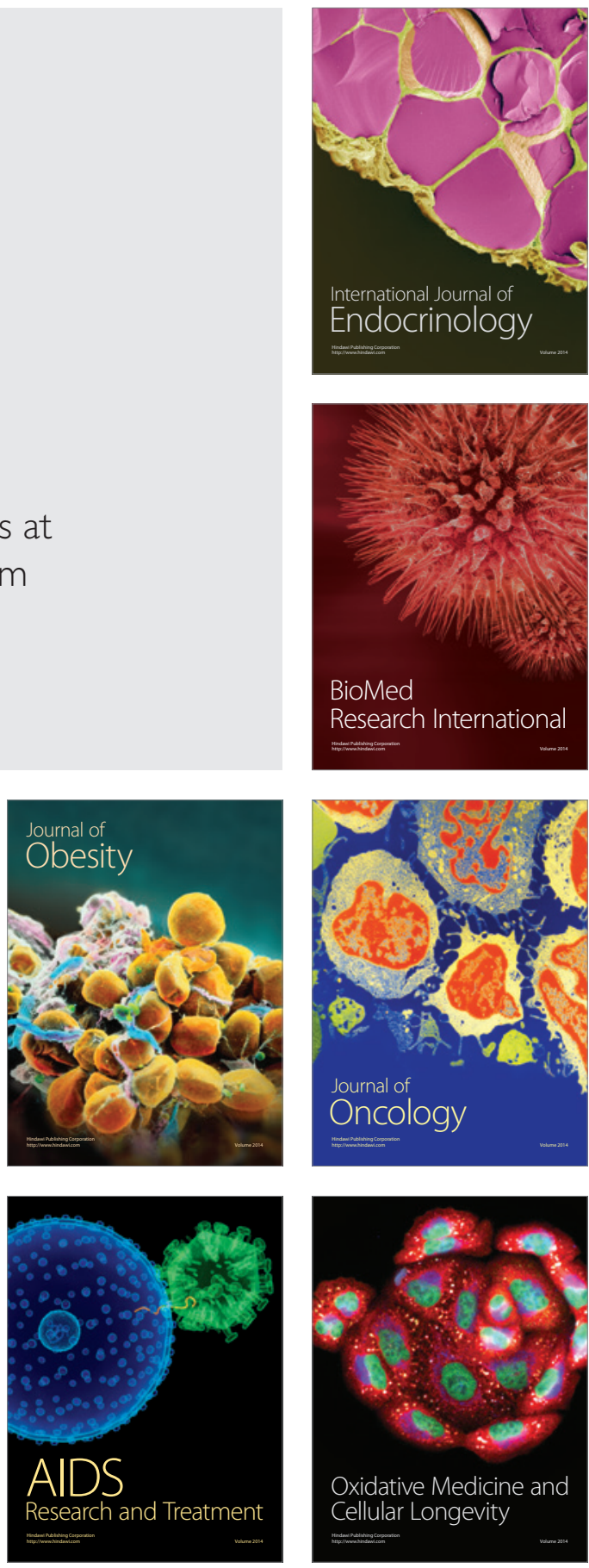